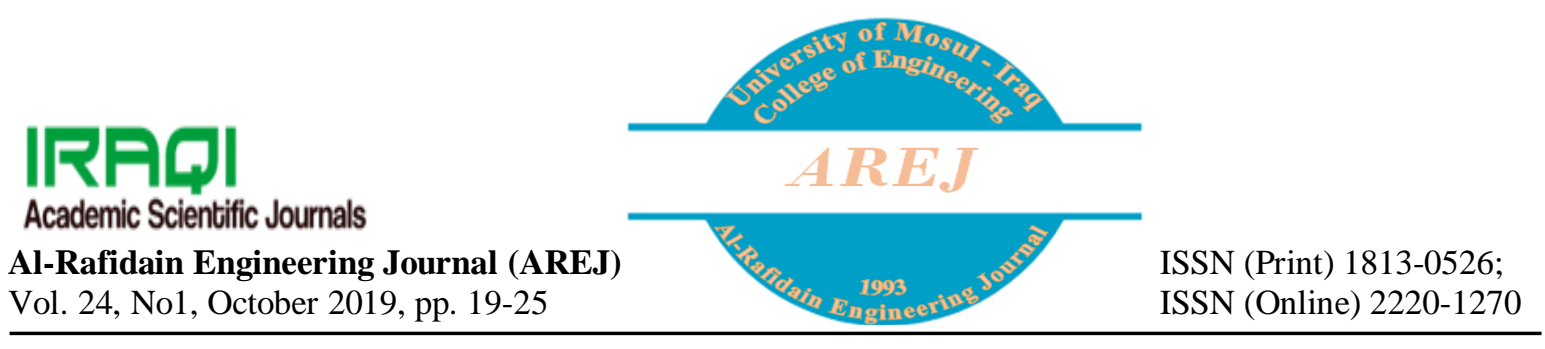

\title{
Buckling Analysis of Hybrid Laminated Composite Beam Analytically and Numerically
}

\author{
Omar A. Mohamed \\ Lecturer \\ Omar.a.mohammed@uomosul.edu.iq \\ Department of Mechanical Engineering, University of Mosul
}

Received: 10-1-2019

Accepted: 30-4-2019

\begin{abstract}
Composite materials become more attractive for researches because of higher strength to weight ratio. As a result, many papers have recently published in this field. The current study deals with improving the resistance of hybrid laminated composite beam under critical buckling load. A number of carbon layers under various orientation angle and positions of hybrid fiber coupled with glass epoxy layers have been studied analytically and numerically. Firstly, an analytical model is presented by using Euler's theory to determine critical buckling load. Then, a 3D finite element models for the composite beams have been simulated by using ANSYS commercial program. The results show a very good agreement between theoretical and FEM (finite volume method). The critical buckling load, shows a proportional with increase the carbon layers number as same time the critical buckling load value shows a valuable decrease when the position of carbon layer insert towards the mid-plane more ever, this value various with orientation angle changing.
\end{abstract}

\section{Keywords:}

Critical buckling load; hybrid composite beam; buckling analysis; FEM.

https://rengj.mosuljournals.com

Email: alrafidain_engjournal@umosul.edu.iq

\section{INTRODUCTION}

Composite materials offer many benefitfeatures such as higher strength to weightratios and low costthat make them particularly suited to develop load bearing components for a variety of applications in the military, naval and aeronautical industries. Some features such as strength, toughness, specificweight, corrosion and wear resistance, and thermal stresses can be developed by the formation of a composite material and orienting the fibers in proper directions. However, there are many degradationphenomena which must be accounted for properly with respect of design laminated composites.

$$
\text { Composite can be }
$$
manufacturing using various types of fibers. The most required properties for fibers are high strength, high stiffness and comparatively low value of density.As it is characterized its low cost and high tensile strength, glass fibers are considered one of main material which is used in low to medium rendering composites. Since long time the idea of using combined materials has been established in order to attend efficient materials. The laminated composite beams which are manufactured using various bonded layers, are considered the most commonly used.Each one of these layers has different properties in different directions. [1].

There are many published research studies to find critical buckling load of different types of composite laminates analytically and using finite element method. Hwang and Mao[2] carried out the buckling behavior of a single-fiber system experimental and 2D finite element method. In this study, hybrid laminate compositesmanufacturing of various types of fiber layers with orientation 
angle of fiber is zero, and different number of fiber layers are used. They studied the effect of size and position of delamination on the buckling load. Ching-Ping[3]. They predicted the buckling load numerically using total strain energy release rate, also they carried out compression test to determine the critical buckling load experimentally. Akbulut and Sayman[4] carried out a buckling analysis of a rectangular composite laminates. Using the first order shear deformation theory, they found the critical buckling loads of composite plates which were designed as symmetric angle-ply and anti-symmetric cross-ply under the in-plane compressive loads for constant or different thicknesses, simple or clamped boundary conditions.Atlihan et al.[5] investigated the effects of stacking sequences of composite laminated beams on critical buckling load and natural frequencies by generalized differential quadrature method and finite element method (FEM). Abdi and Dansehmehr[6] studied the buckling analysis of micro beams by considering Euler-Bernolli and Timeshenko beam theories based on modified couple stress theory for different boundary conditions.

In this paper, the influence of increase number of carbon fiber layers, positions and the orientation angles of fiber for laminated composite beam on the critical buckling load are studied. The hybrid fiber laminated composite material beams have clamped-clamped ends. The beam made of layers from carbon and glass with epoxy. The effect of buckling behaviors are investigated analytically and numerically using the FEM software, ANSYS.

\section{GOVERNING EQUATIONS OF THE \\ MECHANICAL MODEL}

Twelve layers from glass and carbon fibers were bonded together to form the unidirectional multilayer laminated composite beam. The dimensions of the chosen clamped-clamped beam are $400 \mathrm{~mm}, 20 \mathrm{~mm}$ and $3.6 \mathrm{~mm}$ for the length, width and thickness respectively.

The experimental properties data for the laminates fiber reinforced polymer are given in table (1) [7].

Table 1: Properties of carbon with epoxy layer and glass with epoxy layer .

\begin{tabular}{|c|c|c|}
\hline Composite laminate & Carbon/Epoxy & Glass/Epoxy \\
\hline $\mathrm{E} 11(\mathrm{GN} / \mathrm{m} 2)$ & 170 & 77 \\
\hline $\mathrm{E} 22(\mathrm{GN} / \mathrm{m} 2)$ & 15.0 & 39 \\
\hline $\mathrm{v} 12$ & 0.41 & 0.24 \\
\hline $\mathrm{v} 21$ & 0.042 & 0.11 \\
\hline $\mathrm{G} 12(\mathrm{GN} / \mathrm{m} 2)$ & 6.2 & 4.8 \\
\hline $\mathrm{G} 21(\mathrm{GN} / \mathrm{m} 2)$ & 4.1 & 3.2 \\
\hline
\end{tabular}

\begin{tabular}{|l|l|l|}
\hline$\rho(\mathrm{kg} / \mathrm{m} 3)$ & 1510 & 1750 \\
\hline
\end{tabular}

The bending moment $\mathrm{M}$ on the composite beam is shown in Fig. (1) can be written as [8];

$M=\frac{2 b}{3 \rho} \sum_{j=1}^{\frac{m}{2}}\left(E_{x}\right)_{j}\left(z_{j}^{3}-z_{j-1}^{3}\right)$

Where $b$ is width of the beam, $\rho$ is curvature of the beam, $\mathrm{m}$ is the number of layers of the beam, Ex is elasticity modulus of $\mathrm{jth}$ layer and $\mathrm{zj}$ is the distance between the outer face of jth layer and the neutral plane, respectively. The bending moment equation can be written as:

$M=\frac{E_{e f} I_{y y}}{\rho}=E_{e f} I_{y y} \frac{d^{2} w}{d x^{2}}$

And

$E_{e f}=\frac{8}{h^{3}} \sum_{j=1}^{\frac{m}{2}}\left(E_{x}\right)_{j}\left(z_{j}^{3}-z_{j-1}^{3}\right)$

Where Eef is the effective modulus of elasticity, $w$ is the lateral deflection, Iyy is the moment of inertia about the neutral axis of the beam andhis height of the beam.

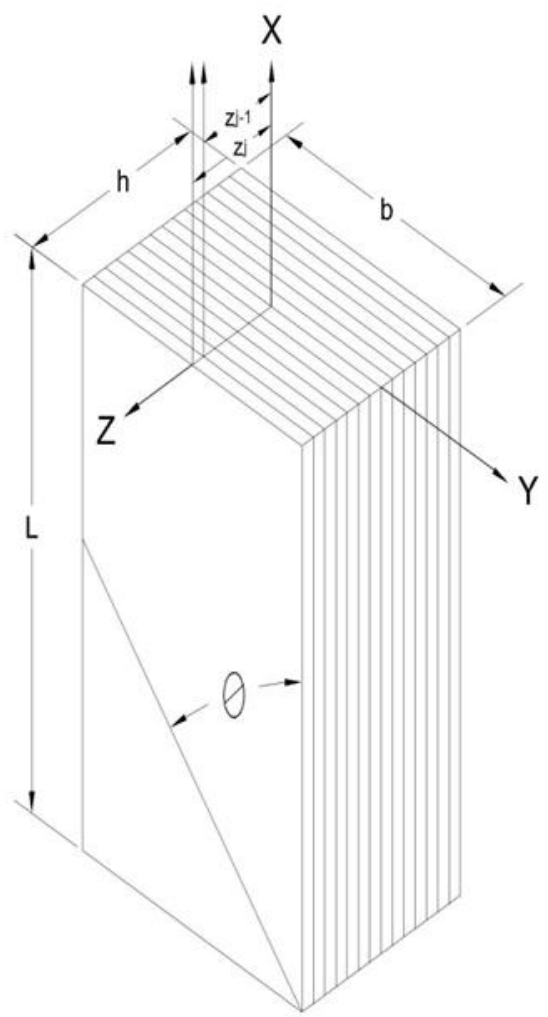

Fig. 1 The geometry of laminated composite beam 
The elastic properties of an angle-ply lamina in which continuous fibers are aligned at an angle $\theta$ with the $\mathrm{x}$-direction can be written as [9]:

$$
\begin{aligned}
& \frac{1}{E_{x x}}=\frac{(\cos \theta)^{4}}{E_{11}}+\frac{(\sin \theta)^{4}}{E_{22}} \\
& +\frac{1}{4}\left(\frac{1}{G_{12}}-\frac{2 v_{12}}{E_{11}}\right) \sin ^{2} 2 \theta
\end{aligned}
$$

$$
\begin{aligned}
& \frac{1}{E_{y y}}=\frac{(\sin \theta)^{4}}{E_{11}}+\frac{(\cos \theta)^{4}}{E_{22}} \\
& +\frac{1}{4}\left(\frac{1}{G_{12}}-\frac{2 v_{12}}{E_{11}}\right) \sin ^{2} 2 \theta
\end{aligned}
$$

$$
\begin{aligned}
\frac{1}{G_{x y}} & =\frac{1}{E_{11}}+\frac{2 v_{12}}{E_{11}}+\frac{1}{E_{22}} \\
& -\left(\frac{1}{E_{11}}+\frac{1}{E_{22}}-\frac{1}{G_{12}}+\frac{2 v_{12}}{E_{11}}\right) \cos ^{2} 2 \theta .
\end{aligned}
$$

$$
=E_{x x}\left[\frac{v_{12}}{E_{11}}-\frac{1}{4}\left(\begin{array}{c}
\frac{1}{E_{11}}+\frac{1}{E_{22}} \\
-\frac{1}{G_{12}}+\frac{2 v_{12}}{E_{11}}
\end{array}\right) \sin ^{2} 2 \theta\right]
$$

A column $\mathrm{CD}$ of length $\mathrm{L}$ fixed at both its ends $\mathrm{C}$ and $\mathrm{D}$ and carrying a critical load at D. As shown in Fig. (2). [10]

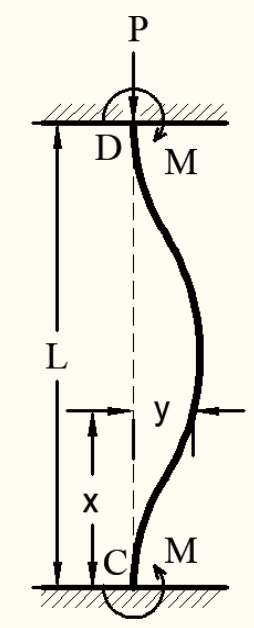

Fig. 2 Column with clamped ends The moment due to the critical load $\mathrm{P}$, $M=-P \cdot y$

$E I \frac{d^{2} y}{d x^{2}}=M-P \cdot y$

$\frac{d^{2} y}{d x^{2}}+\frac{P}{E I} \cdot y=\frac{M}{E I}$

The general solution of the above differential equation can be written as:

$$
\begin{gathered}
y=A \cos \left(x \sqrt{\frac{P}{E I}}\right)+B \sin \left(x \sqrt{\frac{P}{E I}}\right) \\
+\frac{M}{P} \ldots(10)
\end{gathered}
$$

Where $\mathrm{M}$ is fixed end moments at $\mathrm{C}$ and $\mathrm{D}, \mathrm{y}$ is the deflection of the column at $\mathrm{x}, \mathrm{A}$ and $\mathrm{B}$ are the constants of integration.

The solution due to the nonhomogeneous equation consists of both a complementary and particular solution. The boundary conditions are:

At $\mathrm{x}=0, \mathrm{y}=0$, therefore $A=-\frac{M}{P}$

Differentiating the eq. (10) gives,

$$
\begin{aligned}
\frac{d y}{d x}=-A \sqrt{\frac{P}{E I}} \sin \left(x \sqrt{\frac{P}{E I}}\right) \\
+B \sqrt{\frac{P}{E I}} \cos \left(x \sqrt{\frac{P}{E I}}\right) \ldots
\end{aligned}
$$

And at $\mathrm{x}=0, \mathrm{dy} / \mathrm{dx}=0$, therefore

$0=B \sqrt{\frac{P}{E I}}$

Either $B=0$ or $\quad \sqrt{\frac{P}{E I}} \quad$ is equal zero. Since the $\operatorname{load} \mathrm{P}$ is not equal to zero, it is thus obvious that $\mathrm{B}$ is equal to zero. Then substituting the values $\mathrm{A}=\frac{\mathrm{M}}{\mathrm{P}}$ and $\mathrm{B}=0$ in equation (10) we get,

$y=-\frac{M}{P} \cos \left(x \sqrt{\frac{P}{E I}}\right)+\frac{M}{P}$

When $\mathrm{x}=\mathrm{L}, \mathrm{y}=0$ therefore

$0=\frac{M}{P}\left[1-\cos \left(l \sqrt{\frac{P}{E I}}\right)\right]$ 
$\therefore \cos \left(l \sqrt{\frac{P}{E I}}\right)=1$

$l \sqrt{\frac{P}{E I}}=0,2 \pi, 4 \pi, 6 \pi$

The smallest critical load (Euler load), when first mode and $l \sqrt{\frac{P}{E I}}=2 \pi$

$P_{c r}=\frac{4 \pi^{2} E I_{y y}}{L^{2}}$

For laminated composite, the modulus of elasticity is effective modulus (Eef), therefore the critical buckling load can be written as follows after substituting Eq. 3 in Eq. 12.

$P_{c r}=\frac{32 \pi^{2} I_{y y}}{L^{2} h^{3}} \times \sum_{j=1}^{\frac{m}{2}}\left(E_{x}\right)_{j}\left(z_{j}^{3}-z_{j-1}^{3}\right) \ldots$

\section{FINITE ELEMENT MODELING}

As being one of the important tool in almost all the engineering applications to determine the stress analysis, the vibration and fatigue, Finite Element Method (FEM) has been used in this research in order to find out the critical buckling of a laminated composite beams at various composite ratio and orientation values.

The current model was built to be a beam, that has clamped-clamped boundary condition, with hybrid laminated composite material that having twelve layers. Figure (3) presents the generated model which consists of a number of layers with their fiber orientation. After building the required model, eight noded multi-layer shell elements (shell-281), having six degree of freedom at each node was chosen as being a 3-D element modeling of solid structures as shown in Figure (4) and specified for layered applications of a structural shell model in ANSYS 13[11]. This type of element has been utilized because each one of its elements has translations and rotation at each direction which gives a total of six degrees of freedom at each node. After that, the mesh sensitivity was checked in order to ensure an accepted number of elements with 320 elements and 1129 nodes. The material that considered in this work were also specified by considering the glass fiber and the carbon fiber for the inner and the outer layers respectively as shown in Fig (5).

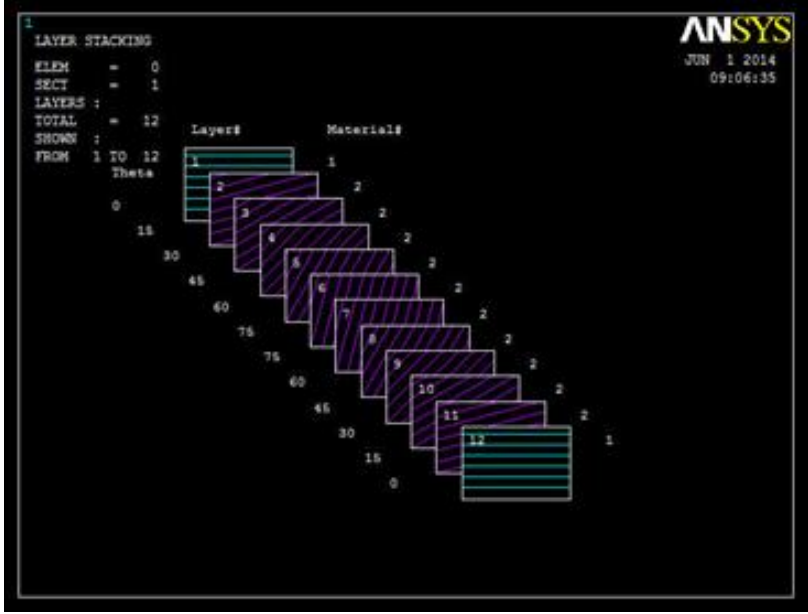

Fig. 3 Laminate section case B2

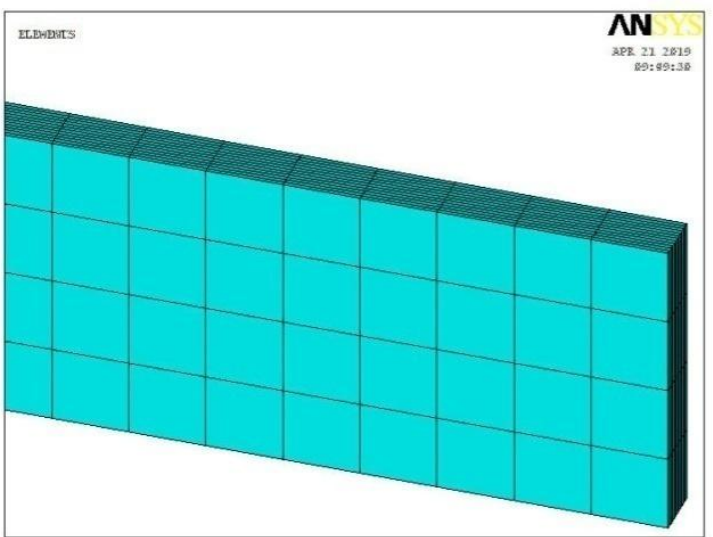

Fig. 4 Meshed model of the beam

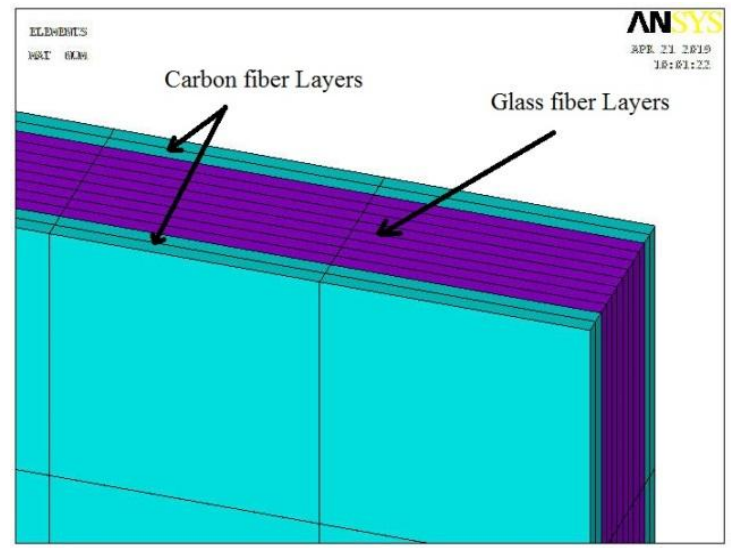

Fig. 5 Sections of laminate

Six cases of laminated beam are considered in this study and listed in Table (2).

Table2: Laminated beam considered in this study

\begin{tabular}{|c|c|c|}
\hline case & Configuration & description \\
\hline $\mathrm{A} 1$ & {$[(\mathrm{G} 0) 6] \mathrm{s}$} & \multirow{5}{*}{$\begin{array}{c}\text { case } A \text { number of } \\
\text { carbon/epoxy layer is } \\
\text { increased with the same } \\
\text { orientation angle }\end{array}$} \\
\hline $\mathrm{A} 2$ & {$[\mathrm{CO} /(\mathrm{GO}) 5] \mathrm{s}$} & \\
\hline A3 & {$[(\mathrm{CO}) 2 /(\mathrm{G} 0) 4] \mathrm{s}$} & \\
\hline A4 & {$[(\mathrm{CO}) 3 /(\mathrm{G} 0) 3] \mathrm{s}$} & \\
\hline A5 & {$[(\mathrm{CO}) 4 /(\mathrm{G} 0) 2] \mathrm{s}$} & \\
\hline
\end{tabular}




\begin{tabular}{|c|c|c|}
\hline A6 & {$[(\mathrm{CO}) 5 / \mathrm{G} 0] \mathrm{s}$} & \\
\hline A7 & {$[(\mathrm{C} 0) 6] \mathrm{s}$} & \\
\hline B1 & {$[\mathrm{CO} /(\mathrm{G} 0) 5] \mathrm{s}$} & \multirow{6}{*}{$\begin{array}{l}\text { case } B \text { altering the position } \\
\text { of carbon layer from top to } \\
\text { mid-plane with the same } \\
\text { orientation angle }\end{array}$} \\
\hline B2 & {$[\mathrm{GO} / \mathrm{CO} /(\mathrm{GO}) 4] \mathrm{s}$} & \\
\hline B3 & {$[(\mathrm{GO}) 2 / \mathrm{CO} /(\mathrm{GO})] \mathrm{s}$} & \\
\hline B4 & {$[(\mathrm{GO}) 3 / \mathrm{CO} /(\mathrm{GO}) 2] \mathrm{s}$} & \\
\hline B5 & {$[(\mathrm{G} 0) 4 / \mathrm{CO} / \mathrm{G} 0] \mathrm{s}$} & \\
\hline B6 & {$[(\mathrm{GO}) 5 / \mathrm{CO}] \mathrm{s}$} & \\
\hline $\mathrm{C} 1$ & {$[\mathrm{CO} /(\mathrm{GO}) 5] \mathrm{s}$} & \multirow{7}{*}{$\begin{array}{l}\text { case } \mathrm{C} \text { varying the } \\
\text { orientation angle of hybrid } \\
\text { laminate contain } 2 \text { layers of } \\
\text { carbon fiber and } 10 \text { layers of } \\
\text { glass fiber from } 0^{\circ} \text { to } 90^{\circ}\end{array}$} \\
\hline $\mathrm{C} 2$ & [C15/(G15)5]s & \\
\hline $\mathrm{C} 3$ & {$[\mathrm{C} 30 /(\mathrm{G} 30) 5] \mathrm{s}$} & \\
\hline C4 & {$[\mathrm{C} 45 /(\mathrm{G} 45) 5] \mathrm{s}$} & \\
\hline $\mathrm{C5}$ & {$[\mathrm{C} 60 /(\mathrm{G} 60) 5] \mathrm{s}$} & \\
\hline $\mathrm{C6}$ & {$[\mathrm{C} 75 /(\mathrm{G} 75) 5] \mathrm{s}$} & \\
\hline $\mathrm{C7}$ & {$[\mathrm{C} 75 /(\mathrm{G} 75) 5] \mathrm{s}$} & \\
\hline$\overline{\mathrm{D} 1}$ & {$[(\mathrm{CO}) 2 /(\mathrm{G} 0) 4] \mathrm{s}$} & \multirow{7}{*}{$\begin{array}{l}\text { case } D \text { varying the } \\
\text { orientation angle of hybrid } \\
\text { laminate contain } 4 \text { layers of } \\
\text { carbon fiber and } 8 \text { layers of } \\
\text { glass fiber from } 0^{\circ} \text { to } 90^{\circ}\end{array}$} \\
\hline D2 & {$[(\mathrm{C} 15) 2 /(\mathrm{G} 15) 4] \mathrm{s}$} & \\
\hline D3 & {$[(\mathrm{C} 30) 2 /(\mathrm{G} 30) 4] \mathrm{s}$} & \\
\hline D4 & {$[(\mathrm{C} 45) 2 /(\mathrm{G} 45) 4] \mathrm{s}$} & \\
\hline D5 & {$[(\mathrm{C} 60) 2 /(\mathrm{G} 60) 4] \mathrm{s}$} & \\
\hline D6 & {$[(\mathrm{C} 75) 2 /(\mathrm{G} 75) 4] \mathrm{s}$} & \\
\hline D7 & {$[(\mathrm{C} 90) 2 /(\mathrm{G} 90) 4] \mathrm{s}$} & \\
\hline E1 & {$[(\mathrm{G} 0) 6] \mathrm{s}$} & \multirow{7}{*}{$\begin{array}{l}\text { Case E varying the } \\
\text { orientation angle of glass } \\
\text { fiber from } 0^{\circ} \text { to } 90^{\circ}\end{array}$} \\
\hline E2 & [(G15)6]s & \\
\hline E3 & {$[(\mathrm{G} 30) 6] \mathrm{s}$} & \\
\hline E4 & {$[(\mathrm{G} 45) 6] \mathrm{s}$} & \\
\hline E5 & {$[(\mathrm{G} 60) 6] \mathrm{s}$} & \\
\hline E6 & {$[(\mathrm{G} 75) 6] \mathrm{s}$} & \\
\hline E7 & {$[(G 90) 6] \mathrm{s}$} & \\
\hline F1 & {$[(\mathrm{CO}) 6] \mathrm{s}$} & \multirow{7}{*}{$\begin{array}{c}\text { case } \mathrm{F} \text { the orientation angle } \\
\text { of carbon fiber varying from } \\
0^{\circ} \text { to } 90^{\circ}\end{array}$} \\
\hline F2 & {$[(\mathrm{C} 15) 6] \mathrm{s}$} & \\
\hline $\mathrm{F} 3$ & {$[(\mathrm{C} 30) 6] \mathrm{s}$} & \\
\hline $\mathrm{F} 4$ & {$[(\mathrm{C} 45) 6] \mathrm{s}$} & \\
\hline F5 & {$[(\mathrm{C} 60) 6] \mathrm{s}$} & \\
\hline F6 & {$[(\mathrm{C} 75) 6] \mathrm{s}$} & \\
\hline F7 & {$[(\mathrm{C} 90) 6] \mathrm{s}$} & \\
\hline
\end{tabular}

\section{RESULTS AND DISCUSSIONS}

The finite element models for the laminated beams having twelve layers are occurred by using finite element software program ANSYS. The numerical results obtained for critical buckling loads of laminated composite beams are compared with analytical results and are found to be consistent with each other.

With increasing the layers number of carbon-epoxy at same orientation angle and reducing the layers number of glass-epoxy for the laminated composite model beam, seven case studies noted as (A1, A2, A3, A4, A5, A6, A7) have been considered in this study. At this point it is important to highlight that increasing the layers number of carbon-epoxy led to higher critical buckling loads as a result of increasing the effective elasticity modulus for the beam as shown in Fig. (6).

Moreover, by altering the carbon layers position, from top to mid-plane at the same orientation angle, the different cases were named as (B1, B2, B3, B4, B5, B6). Here, the critical buckling loads show a remarkable decrease, as illustrated in Fig. (7) that is because the beam's effective elasticity modulus was decreased.

Figs. $(8,9)$ depict the analytical and numerical results for critical buckling load of hybrid laminated composite beam with two and four carbon layers by varying the orientation angle. Fig. (8)shows the hybrid laminated composite beam with two carbon layers, it is noted that the critical buckling load is decreasing sharply with the orientation angle until $\theta=51^{\circ}$, then it is start to increase. With the same mannerFig. (9), the critical buckling load also decreases with the increase the orientation angle, then start to increases but with a less degree as in Fig. (10) because of the increase of carbon layers. The minimum value of the critical load appears at the orientation angle $56^{\circ}$.

The cases (E1, E2, E3, E4, E5, E6, E7) have been investigated in order to compare the buckling analysis of the glass fiber for laminate composite beam at various orientation angle. The values of critical buckling loads decrease more and more by increasing fiber orientation angle from $0^{\circ}$ until about $52^{\circ}$ whereas after $\theta=52^{\circ}$ the value increases, as shown in Fig. (10). The largest critical buckling loads are obtained with fiber orientation angle $0^{\circ}$.

The buckling load of laminated composite beams with different carbon fiber orientation was determined as in cases $(\mathrm{F} 1, \mathrm{~F} 2$, F3, F4, F5, F6, F7). The result shows that the buckling load is decreasing sharply with increase in fiber orientation angle until $\theta=60^{\circ}$ and remains approximately constant from $\theta=60^{\circ}$ to $\theta=90^{\circ}$. It is noticed that the maximum buckling load occurred at $\theta=0^{\circ}$. When the orientation of the fiber changed from $0^{\circ}$ to $30^{\circ}$, the corresponding buckling load was decreased by $84 \%$. The minimum buckling load occurred at $\theta=70^{\circ}$. The variation of buckling load with fiber orientation can be shown in Fig.(11).

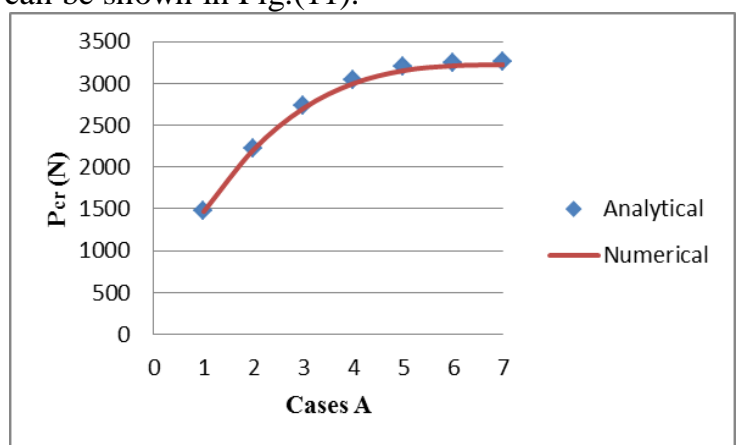

Fig. 6 Effect of increasing carbon layer with same orientation angle on the critical buckling load 


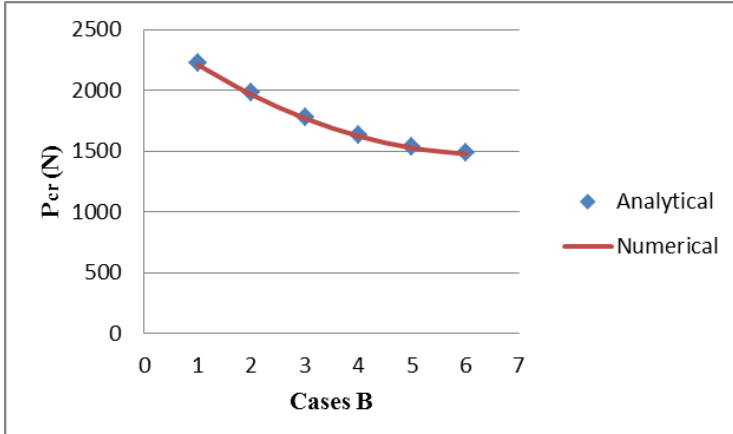

Fig. 7 Effect of varying the position of carbon layer with same orientation angle on the critical buckling load

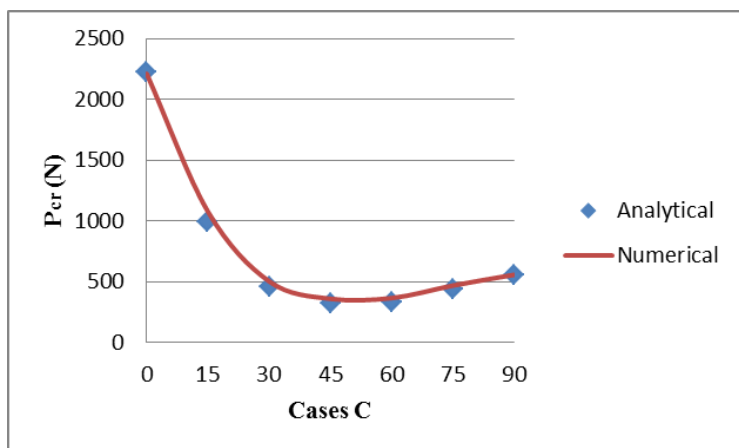

Fig. 8 Effect of orientation angle of hybrid laminate contain 2 layers of carbon fiber and 10 layers of glass fiber on the critical buckling load

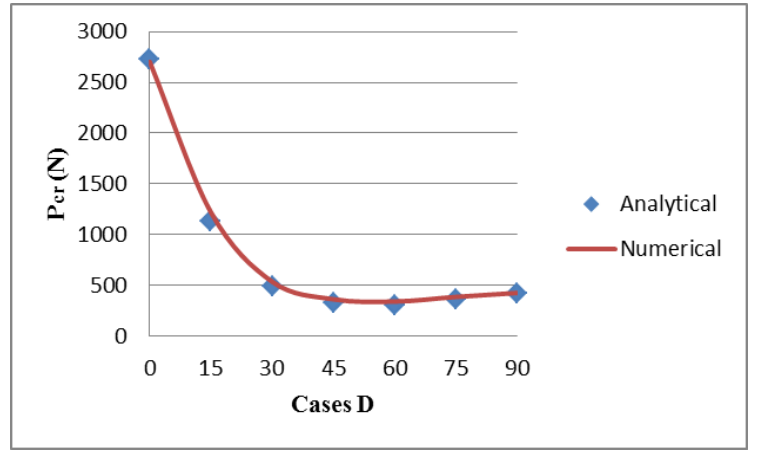

Fig. 9 Effect of orientation angle of hybrid laminate contain 4 layers of carbon fiber and 8 layers of glass fiber on the critical buckling load

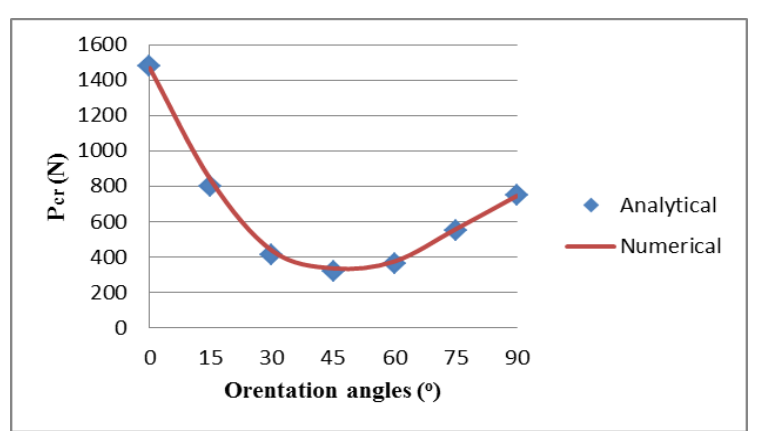

Fig. (10) Effect of orientation angle of glass fiber on the critical buckling load

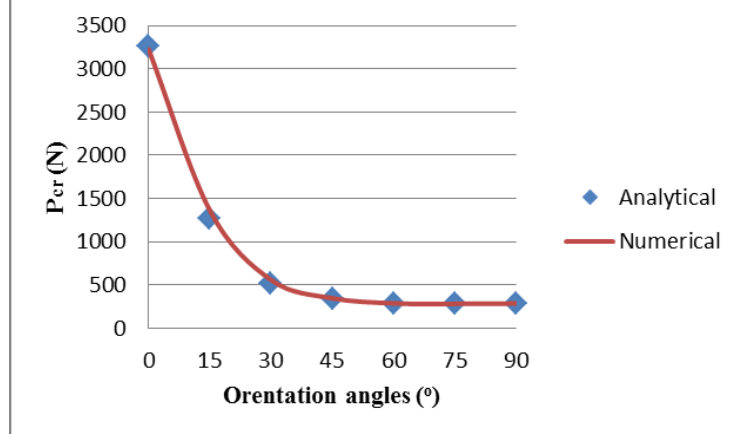

Fig. 11 Effect of orientation angle of carbon fiber on the critical buckling load

\section{CONCLUSION}

1. The critical buckling loads increase when the layers number of carbon-epoxy increases with and without change fiber orientation angle.

2. Significant change in the critical buckling loads occurs with changing the orientation angles of fiber.

3. At same orientation angle, the critical buckling loads decrease with the altering the carbonepoxy layers' position from outer surface towards mid-plane.

4. The largest critical buckling loads values are obtained with fiber orientation angle of zero but the minimum values differ according to the type of fiber.

\section{REFERENCES}

[1] P., Nayak," Vibration Analysis of Woven Fiber Glass/Epoxy Composite Plate", M.Sc. thesis, National Institute of Technology Rourkela, 2008..

[2] S. F. Hwang and C. P. Mao, "buckling delimitation of rectangular containing a crack and made from elastic composite materials" Composite Structure, vol.46, 279-287, 1999.

[3] F. H. Shan and M. Ching-ping, "Failure of delaminated interplay hybrid composite plate under compression", composite science and technology, Vol.24,393-400,2010.

[4] H. Akbulutand O.Sayman "An investigation of laminated plates with central square hole",Reinforced Plastic Composite, vol.20, 1112-1124, 2001.

[5] G. Atlihan, E.Demir, Z.Girginand H.Çallığlu," free vibration and buckling analysis of laminated composite beams", Advanced Composite, vol.18,37-44,2009.

[6] M. M. Abadi, and A. R. Dansehmehr, "An investigation of modified couple stress theory in buckling analysis of micro composite laminated Euler-Bernoulli and Timosheko beams" Journal of engineering science, vol.74, 40-53, 2014.

[7] S. A. Mohmeed, "Experimental study and finite element analysis on delaminated 
buckling of hybrid laminated composites", M.Sc. thesis, Anna University-Chennai, 2012.

[8] R. Gibson, "Principles of composite material mechanics", CRC press, 190-267, 1994.
[9] P. K.Mallick,"Fiber -Reinforced Composites: Materials, Manufacturing and Design", CRC press, 2008

[10] R. S. Khurmi, "Strength of Materials" S.Chand, 2007.

[11] Help of the ANSYS Program V13.

\section{تحليل الاتبعاج لعتبة متر اكبة وهجينة تحليليا وعدديا تحياتي$$
\text { م.عمر عبدالرحمن محمد }
$$

Omar.a.mohammed@uomosul.edu.iq

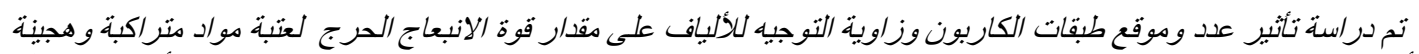

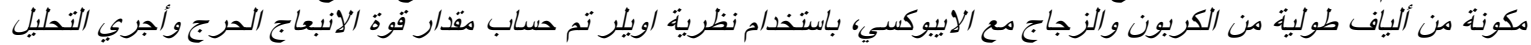

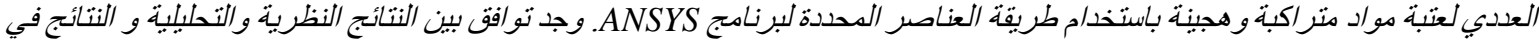

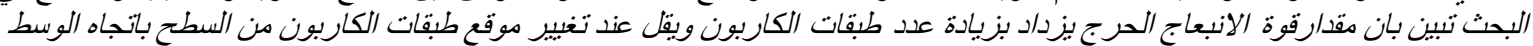

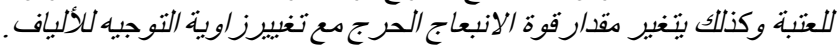

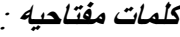

قوة الانبعاج الحرج, عتبة مادة متراكبة, تحليل الأبعاج,طريقة العناصرالمحلدة. 